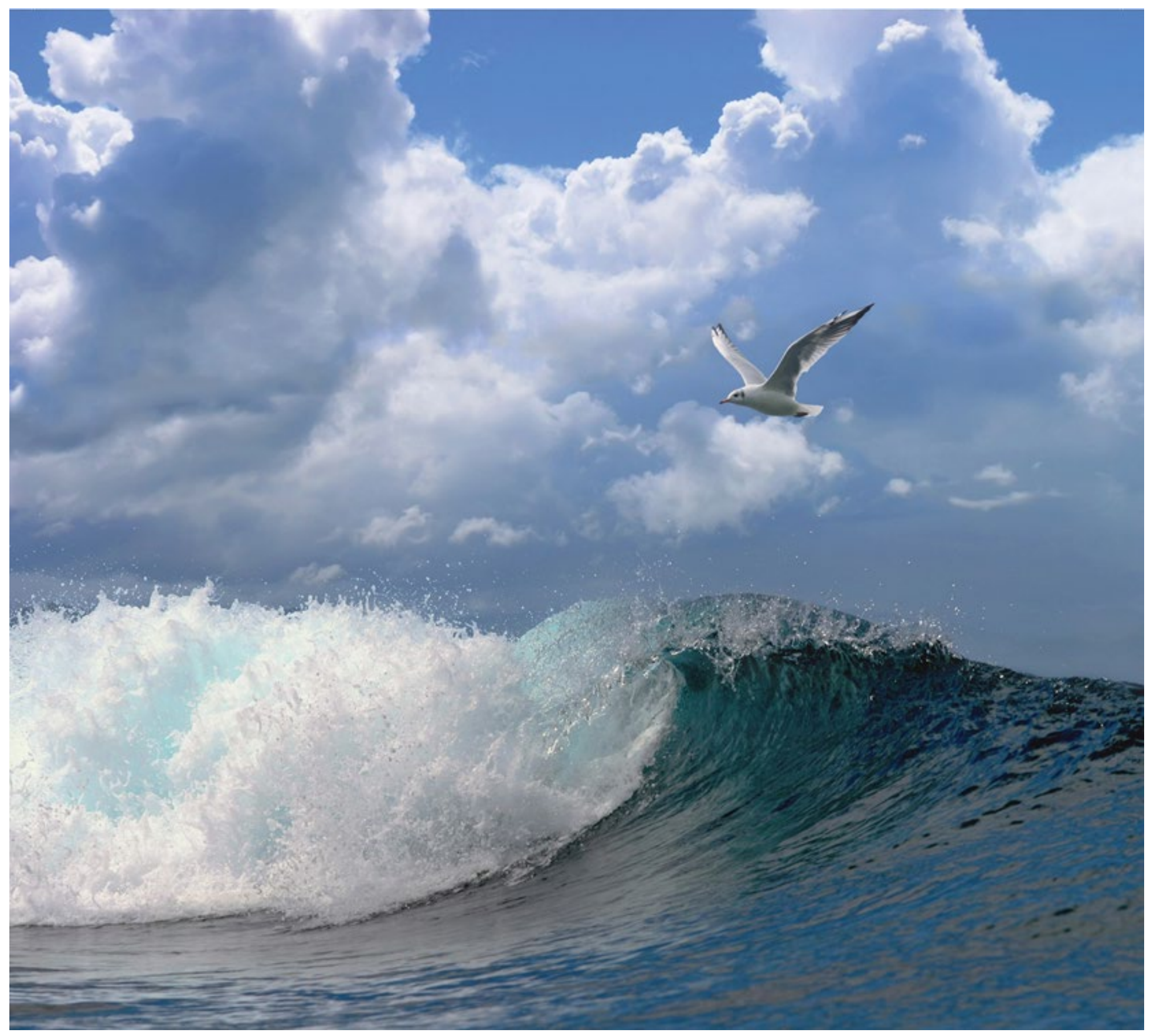

Indicators of the balance between fleet capacity and fishing opportunities: discrepancies between the Dutch national fleet report and STECF 


\section{Indicators of the balance between fleet capacity and fishing opportunities: discrepancies between the Dutch national fleet report and STECF}

Author(s): $\quad$ Esther Beukhof (1), Katell Hamon (2)

1 Wageningen Marine Research

2 Wageningen Economic Research

This research project was carried out by Wageningen Marine Research at the request of and with funding from the Ministry of Agriculture, Nature and Food Quality for the purposes of Policy Support Research Theme 'Natuurinclusieve Visserij' (project no. BO-43-023.02-052). 
Keywords: fleet report, STECF, balance indicators, fleet capacity, fisheries.

Client: $\quad$ Ministry of Agriculture, Nature and Food quality

Attn.: Dirk-Jan van der Stelt

Postbus 20401

2500 EC, Den Haag

BAS code BO-43-023.02-052

This report can be downloaded for free from https://doi.org/10.18174/521470

Wageningen Marine Research provides no printed copies of reports

Wageningen Marine Research is ISO 9001:2015 certified.

\section{(C) Wageningen Marine Research}

Wageningen Marine Research, an institute Wageningen Marine Research accepts no liability for consequential damage, nor within the legal entity Stichting for damage resulting from applications of the results of work or other data Wageningen Research (a foundation under obtained from Wageningen Marine Research. Client indemnifies Wageningen Dutch private law) represented by Dr. Marine Research from claims of third parties in connection with this application. M.C.Th. Scholten, Managing Director All rights reserved. No part of this publication may be reproduced and / or

KvK nr. 09098104, published, photocopied or used in any other way without the written permission WMR BTW nr. NL 8113.83.696.B16.

Code BIC/SWIFT address: RABONL2U IBAN code: NL 73 RABO 0373599285 


\section{Contents}

$\begin{array}{lr}\text { Summary } & 4\end{array}$

1 Introduction $\quad 5$

1.1 Discrepancy between national fleet report and STECF 5

1.2 Approach 6

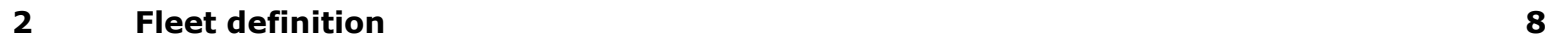

3 Indicators $r$

$\begin{array}{lll}3.1 & \text { Description of indicators } & 10\end{array}$

$\begin{array}{ll}3.1 .1 & \text { Biological indicators }\end{array}$

3.1.2 Technical indicators 12

3.1.3 Economic indicators 13

3.2 Comparison of results of the pelagic fleet segment 15

$\begin{array}{ll}3.2 .1 & \text { Biological indicators }\end{array}$

$\begin{array}{ll}\text { 3.2.2 Economic and technical indicators } & 15\end{array}$

3.3 Comparison of fleet report methods with STECF 16

3.3.1 Biological indicators 16

$\begin{array}{lll}3.3 .2 & \text { Technical indicators } & 17\end{array}$

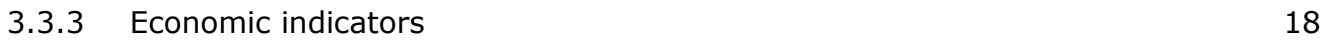

3.4 Comparison of new fleet report methods with STECF 18

3.4.1 Biological indicators 19

$\begin{array}{lll}3.4 .2 & \text { Technical and economic indicators } & 21\end{array}$

$4 \quad$ Conclusion and Recommendations 23

$\begin{array}{lr}\text { References } & 26\end{array}$

$\begin{array}{lr}\text { Acknowledgements } & \mathbf{2 7}\end{array}$

$\begin{array}{lr}\text { Justification } & 28\end{array}$ 


\section{Summary}

The STECF expert working group (EWG) on balance between fleet capacity and fishing opportunities reviews every year the national fleet reports on balance indicators and action plans of Member States. Member States have to calculate a range of biological, economic and technical indicators that are described in the Commission guidelines $\operatorname{COM(2014)~545.~As~part~of~the~review~of~the~fleet~reports,~the~}$ EWG independently calculates the indicators, and reports back their findings to the European Commission. Fleet segments that are out of balance require an action plan from Member States to restore the balance between fleet capacity and fishing opportunities.

The 2019 report of the Balance Expert Working Group, STECF-19-13, paid particular attention to the discrepancy in indicators values between the national fleet reports and their own calculations for the year 2017. They observed that the Netherlands used a different fleet segmentation, thereby making comparisons difficult. Furthermore, they found large differences in the two biological indicators and some small differences in the economic indicators, which in some cases even indicated a different state of balance compared to what the Dutch national fleet report concluded. This report therefore investigated the discrepancy in balance indicator values from 2017, with the aim to explain the observed differences and to re-calculate the indicators for the national fleet report for the 2017 data with the same fleet segmentation and methods as STECF-19-13.

For the biological indicators, differences in indicator values were caused by a wrong interpretation in the Dutch national fleet report of the equations in the 2014 Commission guidelines. Furthermore, not all stocks that were fished upon by fleet segments were included in the analysis of the fleet report, thereby excluding stocks that were still overexploited. Different procedures on how to divide the landings data by species over the stocks may also have led to the discrepancy in biological indicators.

Differences in the economic indicators were small compared to the biological indicators, and both the fleet report and STECF-19-13 came to the same conclusions regarding the balance of the fleet from an economic point of view. The small discrepancies were caused using different interest rates and real values. No difference in technical indicators was observed for the pelagic fleet segment.

Redoing the calculations for the national fleet report with the 2017 data and the same fleet segmentation as STECF led to the same or very similar values for most indicators. Future work is needed in close cooperation with the Balance EWG to make sure that the methods are aligned with both the Commission guidelines and STECF. This is particularly applies to the biological indicators, for which some small differences with the STECF values were still observed after improving the methods.

Based on the findings in this report, it is recommended to become more actively involved in the Balance EWG, preferably by having somebody with biological expertise attending future EWG meetings who can solve the remaining issues in the national fleet report calculations and avoid any discrepancies in the future. Furthermore, the biological section of the national fleet report should include time series of the biological indicators, as management measures may take time before the desired state and balance are reached. Future fleet reports should also use a landings data splitting procedure tailored to the year of interest and to the Dutch landings. Regarding the economic and technical indicators, it is recommended to use both the STECF fleet segmentation (to allow for comparison with the EWG) and the clustered segmentation to ensure that local knowledge and context of the fleet is provided, as the data of particularly the small-scale fleet segment, and therefore also its indicators, need to be interpreted with caution. 


\section{Introduction}

Member states of the EU are required to deliver an annual report on the balance between the fishing capacity of the national fleet and its fishing opportunities in accordance with Article 22 of Regulation (EU) No 1380/2013. These national fleet capacity reports should contain a number of indicators reflecting the balance of the fleets with the status of the fish stocks that the fleets fish upon. Guidelines for the calculation of the indicators are described in the Commission guidelines COM(2014)545 (hereafter referred to as the 2014 Commission guidelines). The Balance expert working group (EWG) of the Scientific, Technical and Economic Committee for Fisheries (STECF) is requested each year to review all national fleet reports and action plans to assess if they are in line with the Commission guidelines. An action plan is required when the balance indicators point towards an overcapacity of the fleet and an imbalance with fishing opportunities. Member states should then provide an action plan describing which measures and actions they plan to take in order to achieve balance again. These action plans are reviewed by the EWG as well. The EWG also evaluates and provides recommendations for the suitability and interpretability of the balance indicators.

The balance indicators that Member States are required to calculate can be divided into biological, economic and technical indicators. The biological indicators reflect to what extent a fleet is fishing on stocks that are at high biological risk due to, for instance, a low stock size or productivity. An overcapacity of the fleet regarding to such a stock at risk may lead to overfishing and should be avoided. The economic and technical indicators evaluate if fleets are able to cover their costs in the short-term and if they are economically viable in the long-term. They also include social indicators, such as wage of the crew, and vessel-use indicators that reflect the number of active and inactive vessels in a fleet. The 2014 Commission guidelines emphasize that a single indicator should not be used to assess the balance and capacity of an entire fleet. Instead, one should look at multiple indicators, at different fleet segments and at the trend in indicators over time. The indicators are therefore not calculated for the entire national fleet, but for fleet segments separately.

\subsection{Discrepancy between national fleet report and STECF}

As part of the review of the national fleet reports the Balance EWG calculates the indicators independently. Their most recent report, STECF-19-13 (STECF, 2019a), particularly paid attention to the differences found between the indicator values that member states reported over 2017 and those the EWG calculated themselves. For the comparison with the Dutch fleet report, it appeared that indicators could most often not be compared, because in the fleet report the Netherlands used a different fleet segmentation by grouping some of the fleet segments used by STECF. STECF uses the fleet segments from the economic data call that are defined by Wageningen Economic Research (see differences in Table 1). Furthermore, for the fleet segments and indicators that could be compared, the Netherlands reported different values in several cases (Table 2). Some indicators differed to such an extent that the Dutch fleet report and STECF-19-13 came to a different status of the balance between the capacity of a fleet segment and its fishing opportunities. For instance, the pelagic fleet segment and the large demersal beam trawlers were evaluated by the Netherlands as in balance with regards to the Sustainable Harvest Indicator (value $<1$ ), whereas the EWG concluded the opposite (value $>1$; see Table 2).

Overall, the Netherlands summarized in their national fleet report over the year 2017 that "there is no significant imbalance between fleet capacity and fishing opportunities. The economic, social and sustainable harvest indicators [...] are quite positive, with no stocks exploited at high levels of biological risk." (p. 4). However, STECF-19-13 found several biological and economic indicators, at least for one fleet segment, that suggested imbalance. Based on these findings, the Netherlands is requested by the 
European Commission to come up with an action plan to reduce the apparent structural overcapacity for part of the fleet.

\section{Table 1}

Segmentation of the Dutch fleet as used by the expert working group of STECF and by the Netherlands in their national fleet report. Fleet names for STECF are composed of the main gear: TBB = beam trawls, $P G=$ passive gear, $D F N=$ drift and/or fixed netters, $P G=$ passive gear, DTS = Demersal trawls and seines, $T M=$ midwater trawls, and the vessel length $(V L)$ category in meters $(0-10 \mathrm{~m}, 10-12 \mathrm{~m}, 12-18 \mathrm{~m}$, $18-24 m, 24-40 m,>40 m)$.

\begin{tabular}{|c|c|}
\hline STECF & The Netherlands \\
\hline TBB VL0010 & \multirow{4}{*}{ Small scale } \\
\hline DFN VL1824 & \\
\hline PG VL0010 & \\
\hline PG VL1012 & \\
\hline DTS VL1824 & \multirow{2}{*}{ Demersal } \\
\hline DTS VL2440 & \\
\hline TBB VL1218 & \multirow{2}{*}{$\begin{array}{c}\text { Small beam } \\
\text { trawlers }\end{array}$} \\
\hline TBB VL1824 & \\
\hline TBB VL2440 & \multirow{2}{*}{$\begin{array}{c}\text { Large beam } \\
\text { trawlers }\end{array}$} \\
\hline TBB VL40XX & \\
\hline TM VL40XX & Pelagic \\
\hline
\end{tabular}

\section{Table 2}

2017 values for indicators that STECF-19-13 reported to be different from what the Netherlands calculated in the national fleet report. Note that the Netherlands grouped certain fleet segments.

\begin{tabular}{llcc}
\multirow{2}{*}{ Indicator } & Fleet segment & National fleet report & STECF-19-13 \\
Sustainable Harvest Indicator & TM VL40XX & 0.83 & 1.13 \\
\cline { 2 - 4 } & TBB VL2440 & 0.89 & 1.03 \\
\cline { 2 - 4 } Stock-at-risk indicator & TBB VL40XX & 1 & 1.05 \\
\hline \multirow{2}{*}{ Return on Investment (ROI) } & TM VL40XX & 0 & 2 \\
\cline { 2 - 4 } & PG VL0010 & Pooled with other fleet & -2.2 \\
\cline { 2 - 4 } Break Even Revenue & TBB VL0010 & Small scale - Not provided & -0.2 \\
\hline & DTS VL1824 & Pooled with other fleet & 1 \\
\hline
\end{tabular}

This report will look into the discrepancies between the indicator values that were found between the Dutch national fleet report and STECF-19-13. This includes comparing the methods and recalculating the indices for the national fleet report with the same segmentation and methods that the STECF has been using. Understanding the discrepancies and recalculating the indicators is necessary to avoid any discrepancies in the future.

\subsection{Approach}

This report, and therefore also the approach taken here, is structured as follows. First, a more detailed description will be given in Chapter 2 of the definition and segmentation of the fleets as done by STECF and by the Netherlands, and we discuss what the implications are of aggregating landings data by one or the other approach for the reliability of the indicators.

Chapter 3 will focus on the discrepancy in indicators due to potential differences in methods and calculations. Section 3.1 starts off with a description of the indicators, how they are calculated and how they should be interpreted. Section 3.2 presents the indicators of the pelagic fleet segment for the year 2017 as calculated by the EWG in STECF-19-13 and as calculated in the Dutch national fleet report. The 
pelagic segment is chosen because it is the only segment that is the same in the fleet report and in STECF-19-13, and therefore serves as a good illustration of how differences in data handling and calculation of the indicators have led to the observed discrepancies. Section 3.3 will try to explain these discrepancies between STECF-19-13 and the national fleet report by evaluating and comparing the methods. Section 0 will present a new version of the indicator values of the national fleet report for 2017, but with the same fleet segmentation as STECF and with improved methods that closely follow the Commission guidelines and the methods described in STECF-19-13. Finally, this report ends with a summary of the main results, and some final conclusions and recommendations. 


\section{Fleet definition}

Fleets used in STECF are fleets defined following the Data Collection Framework (DCF). They are defined based on six vessel length categories (0-10m, 10-12m, 12-18m, 18-24m, 24-40m and above 40m) and on the main gear used. The fleets for the Netherlands are defined by Wageningen Economic Research when they provide the economic data for the Annual Economic Report.

The fleet segmentation previously used in the fleet report matches the fleet segmentation used in the annual reports made by Wageningen Economic Research (former LEI), "fisheries in figures" (Taal et al. (2010) for the final report version and www.visserijincijfers. $n l$ for recent information). In these reports, the marine fleets are broadly divided in three categories (mussel, oysters and cockle vessels were separated as "coastal fisheries") based on how economic data is collected, see also Table 3:

- The small scale fisheries have a value of landing lower than $€ 50.000$ per vessel and per year based on logbook information and/or when they use passive gears. Economic information from those vessels is obtained through a questionnaire sent every year to the vessel owners. The data obtained gives an indication but should be used with caution as the quality is highly variable in time. This is the reason why those fleets where previously not included in the economic part of the fleet report.

- The cutter fishery is the most studied part of the fleet. For a representative panel of those vessels, Wageningen Economic Research collects detailed economic data (down to the trip data for variable costs). The main gear used by those vessels is the beam trawl targeting either shrimp (smaller vessels) or flatfish (small and large vessels) depending on the mesh size used. Those vessels are divided in two categories according to their engine power in "fisheries in figures" (lower and higher than 300HP), which is broadly translated into small beam trawlers and large beam trawlers using the length categories shown in Table 3. Some vessels of the cutter fleet use other demersal gears than beam trawls (or their modern variants such as sumwing or pulse trawls) and are then grouped in the demersal fleet.

- The pelagic fleet (TM 40XX) is the only fleet identified in the exact same way in the STECF data and the fleet report. Those vessels have a completely different cost structure, they are large freezer trawlers targeting small pelagic fish that is processed directly onboard. This is the only Dutch fleet active outside the Greater North Sea and the English Channel. The data are collected directly from the fishing companies once a year.

\section{Table 3}

Data source for the different fleet segmentations of the Dutch fleet as used by the expert working group of STECF and by the Netherlands in their national fleet report.

\begin{tabular}{|c|c|c|c|c|}
\hline STECF & The Netherlands & Number of ves & els in 2017 & Data source \\
\hline TBB VL0010 & \multirow{4}{*}{ Small scale } & 27 & \multirow{4}{*}{219} & \multirow{4}{*}{ Questionnaires } \\
\hline DFN VL1824 & & 13 & & \\
\hline PG VL0010 & & 161 & & \\
\hline PG VL1012 & & 18 & & \\
\hline DTS VL1824 & \multirow{2}{*}{ Demersal } & 8 & \multirow{2}{*}{35} & \multirow{6}{*}{ Panel } \\
\hline DTS VL2440 & & 27 & & \\
\hline TBB VL1218 & \multirow{2}{*}{ Small beam trawlers } & 23 & \multirow{2}{*}{178} & \\
\hline TBB VL1824 & & 155 & & \\
\hline TBB VL2440 & \multirow{2}{*}{ Large beam trawlers } & 27 & \multirow{2}{*}{85} & \\
\hline TBB VL40XX & & 58 & & \\
\hline TM VL40XX & Pelagic & 8 & 8 & Annual reporting \\
\hline
\end{tabular}

The size of the fleets differs greatly (Table 3 ). The aggregation previously made ensured that the economic data coverage was sufficient for all fleets. Some fleets have only a few vessels and fall for some years under the 10 vessels threshold that is usually used to ensure confidentiality of data. In 2017 
two fleets had only eight vessels and the Netherlands is not obliged to provide economic data for those (but we do to ensure the continuity of time series). 


\section{Indicators}

\subsection{Description of indicators}

\subsubsection{Biological indicators}

There are two biological indicators that need to be calculated following the 2014 Commission guidelines: the Sustainable Harvest Indicator (SHI) and the stocks-at-risk (SAR) indicator. Both will be explained separately below, including a short review on their interpretation and reliability.

\section{Sustainable Harvest Indicator (SHI)}

The SHI reflects the extent to which a fleet segment depends on overfished stocks. Here, 'overfished' means that a stock is fished at a fishing mortality rate above FMSY, which is the fishing mortality rate corresponding to maximum sustainable yield (MSY). Where FMSY is defined as a range, exceeding the upper end of the range is interpreted as 'overfishing'.

Data requirements for the SHI are full biological assessments (during which the current fishing mortality is determined) of the stocks that are fished, estimates of $F_{M S Y}$, or existing proxies to it (FMAX or $F_{0.1}$ ), and the value of the landings of the stocks. Where a fleet segment fishes a single stock, the indicator is calculated as:

$$
\frac{F}{F_{M S Y}}
$$

where $F$ is the most recent value of fishing mortality available from a scientific assessment. When a fleet segment catches a number of species $(n)$, then the indicator is an average of the indicator above for each stock $(i)$, weighted by the value of the landings for that stock $\left(V_{i}\right)$. The indicator is then calculated as:

$$
\frac{\sum_{i=1}^{i=n} V_{i} \frac{F_{i}}{F_{M S Y, i}}}{\sum_{i=1}^{i=n} \sum V_{i}}
$$

where $F_{i}$ is the most recent value of fishing mortality of stock $i$ available from a scientific assessment, $F_{M S Y, i}$ the fishing mortality at maximum sustainable yield of stock $i$, and $V_{i}$ the value of the landings of stock $i$.

This indicator performs in the same way whether the fleet segment makes catches from different stocks in the same fishing operations or whether this occurs in a sequence of different targeted fisheries within the same fishing year.

The calculation of SHI depends on the availability of quantified scientific advice for the stocks in question. In cases where more than $60 \%$ of the value of the landings is made up of stocks for which values of $F$

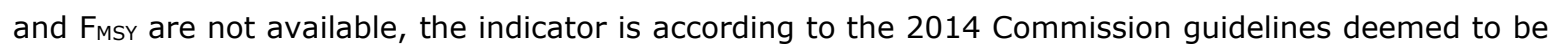
unavailable.

\section{Interpretation}

The 2014 Commission guidelines state that a value above 1 indicates that a fleet segment, on average, fishes structurally on (and generates income from) stocks that experience exploitation levels above of what is deemed sustainable. If SHI is above 1 for three years in a row, the fleet segment could be considered to be in imbalance with its fishing opportunities. A shorter time period applies to small pelagic species. 
In their review of the interpretation and reliability of the indicators, the EWG has expressed some concerns regarding the SHI, and has given some recommendations for improvement (see p.12-14 in STECF-19-13). Some important concerns and recommendations are listed below:

- Used in isolation, the SHI can be misleading, because: (i) it does not take into account to what extent a fleet segment relies on a stock, and (ii) it does not provide an indication of the overall contribution of a fleet segment to the total landings of an overfished stock.

- $\quad$ SHI can have a value below 1 , despite that a fleet segment fishes on individual stocks that are overfished.

- Several stocks have management plans with FMSY ranges rather than a fixed value. In such cases, the SHI uses the upper value of the range. The SHI could be improved by taking the entire range into account rather than its upper value only.

- $\quad$ The Common Fisheries Policy states that FMSY should be achieved for all stocks by latest 2020. When SHI is above 1 in a certain year before 2020, it may reflect the outcome of political decisions to reach FMSY not immediately, but by 2020.

- An SHI may flag a signal of imbalance for a fleet segment, even though another fleet segment is the main cause of the overexploitation of a certain stock.

- $\quad$ SHI values calculated for different fleet segments may not be comparable. Smaller vessels tend to fish on fewer stocks than larger vessels. Therefore, fleet segments of smaller vessels may reach $\mathrm{SHI}>1$ more easily, since one overfished stock may already cause it to be above 1 . Fleet segments with larger vessels that target more stocks and cover different areas could be less sensitive to the overexploitation of particular stocks.

\section{Stocks-at-risk indicator (SAR)}

The stocks-at-risk indicator counts the number of stocks that are exploited by the fleet and that are assessed as being at high biological risk. In this context, 'exploited by' means that:

- The fleet segment takes $10 \%$ or more of the total landings (in weight) of a particular stock; or

- The landings (in weight) of the fleet segment consist of $10 \%$ or more of a particular stock

A stock at high biological risk means that a stock is:

A. assessed as being below the Blim biological level; or

B. subject to an advice to close the fishery, to prohibit directed fisheries, to reduce the fishery to the lowest possible level, or similar advice from an international advisory body, even where such advice is given on a data-limited basis; or

C. subject to a fishing opportunities regulation which stipulates that the fish should be returned to the sea unharmed or that landings are prohibited; or

D. a stock which is on the IUCN "red list" or is listed by CITES.

The SAR indicators count the number of stocks that are exploited and for which one or more of the above risk criteria ( $A$ to $D$ ) apply. It can be expressed for each fleet segment as:

$$
\sum_{i=1}^{i=n}\left(1 \text { if }\left(C_{i}>0.1 C_{t}\right) \text { or }\left(C_{i}>0.1 T_{i}\right) ; \text { otherwise } 0\right)
$$

where $C_{i}$ is catch of stock $i, C_{t}$ total catch of all stocks taken by the fleet segment, $T_{i}$ total catch of stock $i$ taken by all segments, for $n$ stocks that fall into any one of categories $A$ to $D$ above.

\section{Interpretation}

If a fleet segment has a SAR indicator value of 1 or higher (i.e. it catches one or more stocks at risk), this could be an indicator of a potential capacity imbalance, according to the 2014 Commission guidelines.

In their review of the interpretation and reliability of the indicators, the EWG has expressed some concerns regarding the SAR indicator and has given some recommendations for improvement (see p.1416 in STECF-19-13). Some important concerns and recommendations are listed below:

- The EWG does not fully agree with the interpretation from the 2014 Commission guidelines, stating that SAR is an indicator of imbalance of the capacity of a fleet segment. They would 
rather interpret it as a sign that a fleet segment is worthy of further investigation to determine if it is in balance with its fishing opportunities.

- The EWG considers $B_{p a}$ to a better limit to determine if a stock is below safe biological limits than $B_{\text {lim, }}$ which is currently used as a criterion for a stock to be at risk. $B_{p a}$ corresponds to the spawning stock biomass at which there is a high probability that the stock is above $B_{\lim }$ and considers the uncertainties in stock assessments.

- The $10 \%$ threshold for determining if a fleet segment is exploiting a stock or not is arbitrary and has not been tested. A sensitivity analysis with different thresholds is therefore needed.

- The threshold of catching more than $10 \%$ of the total landings of a stock is only based on landings by the EU fleet, i.e. landings by non-EU countries are not included in the total landings. The impact of fleets from EU member states may thus be overestimated.

- Members of the EWG experienced that the interpretation of criteria $A$ to $D$ was sometimes subjective.

\subsubsection{Technical indicators}

\section{Inactive vessel indicator}

The inactive vessel indicator $\left(I V I_{v l}\right)$ measures the proportion of unused and dormant fishing capacity of the national fleet. The indicator is calculated for each vessel length category $(v /)$ following the DCF categories: $0-10 \mathrm{~m}, 10-12 \mathrm{~m}, 12-18 \mathrm{~m}, 18-24 \mathrm{~m}, 24-40 \mathrm{~m},>40 \mathrm{~m}$. The inactive vessel indicator is the proportion of vessels inactive (for the whole year) over the total fleet calculated as percentage in number of vessels ( $n b$, equation 1$)$, percentage in engine power ( $k W$, equation 2$)$ and percentage in gross tonnage (GT, equation 3).
1) $I V I_{v l}^{n b}=\frac{\text { TotVes }_{\text {inactive, } v l}}{\sum_{g, v l} \text { TotVes }_{g, v l}} \cdot 100$
2) $I V I_{v l}^{k W}=\frac{T o t K W_{\text {inactive, } v l}}{\sum_{g, v l} \text { TotKW }_{g, v l}} \cdot 100$
3) $I V I_{v l}^{G T}=\frac{\operatorname{TotGT}_{\text {inactive, } v l}}{\sum_{g, v l} \operatorname{TotGT}_{g, v l}} \cdot 100$

Where TotVes is the number of vessel per fleet, $g$ is the fishing technique (including inactive), TotKW is the total engine power per fleet in $\mathrm{kW}$ and TotGT is the total gross tonnage per fleet in tonnes.

\section{Interpretation}

The higher the inactive vessel indicator, the higher the capacity that is available but not used in the fishery, being a risk of overcapacity. Values higher than $20 \%$ are described as 'out of balance'.

In their review of the interpretation and reliability of the indicators, the EWG has expressed some concerns regarding the inactive vessel indicators, and has given some recommendations for improvement (see p.18 in STECF-19-13). Their concerns and recommendations are listed below:

- In some MS (esp. in the Mediterranean) there is high 'inactivity' for various reasons: many small vessels only operate part time / on a seasonal basis; fishers may own several boats, some of which are used as stand-by vessels for various reasons (see Finland / Italy /Malta 2015 annual reports).

- EWG 16-09 (STECF 2016) considers that technical indicators should always be interpreted with caution, and that local expert knowledge is generally required to accurately interpret indictor results/trends. This is in particular the case for small-scale fleet segments.

\section{Vessel utilization ratio}

The vessel utilization ratio (VUR) represents how much active vessels are utilised in a year compared to the maximum utilization seen in the fleet of vessels of the same size using the same fishing technique. The maximum days at sea within the fleet is the average of the 10 most active vessels of the fleet. Alternatively, if that maximum days at sea is unavailable, a proxy of 220 days can be used to calculate the $V U R_{220}$. However, maximum days at sea is preferred to a theoretical 220 days as fishing days might be limited due to weather conditions, vessel size or seasonality in fishing activity due to biological reasons.

The vessel utilization ratio is calculated for all active fleets as the proportion of average days at sea on the maximum days at sea used in the fleet: 


$$
\begin{gathered}
V U R=\frac{\text { average days at sea }}{\text { maximum days at sea }} \\
V U R_{220}=\frac{\text { average days at sea }}{220}
\end{gathered}
$$

\section{Interpretation}

The higher the indicator, the more efficiently a fleet is used. A traffic light system is used by the Balance working group of STECF with values higher than $90 \%$ in green, between 70 and $90 \%$ in orange and lower than $70 \%$ in red.

In their review of the interpretation and reliability of the indicators, the EWG has expressed some concerns regarding the inactive vessel indicators, and has given some recommendations for improvement (see p.18 in STECF-19-13). The relevant concerns for the Netherlands and recommendations are listed below:

- In some Member States vessel use within fleet segments is not homogenous because only parts of the fleet are fishing full time for various reasons (e.g. fleet segments include a proportion of part-time fishers; older vessels being inactive during periods of maintenance or repair, breaks imposed on parts of fleet segments due to management measures with some vessels compensating by targeting other stocks and others remaining inactive).

- EWG 16-09 considers that technical indicators always be interpreted with caution, and that local expert knowledge is generally required to accurately interpret indictor results/trends. This is in particular the case for small-scale fleet segments.

\subsubsection{Economic indicators}

\section{Current revenue to break-even revenue ratio ( $C R / B E R)$}

The ratio between the current revenue and break-even revenue measures the economic capability of fishing fleets to keep fishing, i.e. does the revenue cover the operating costs and salaries?

$$
\frac{C R}{B E R}=\frac{\text { Current Revenue }}{\text { BreakEvenRevenue }}
$$

where CurrentRevenue $=$ totlandginc + tototherinc

and

$$
\text { BreakEvenRevenue }=\frac{\text { FixedCosts }}{1-\text { VariableCosts/CurrentRevenue }}
$$

where

FixedCosts $=$ totnovarcost + totdepcost + Oppcost

and

VariableCosts $=$ totcrewwage + totunpaidlab + totenercost + totrepcost + totvarcost

In those equations, all indicators are taken from the data call on economic data (2019 Data call for economic and social datasets on the EU fishing fleets - MARE/A4/ASC(2019)) with the exception of the opportunity costs of capital Oppcost. totlandginc is the income from landing, tototherinc is the other income, totnovarcost are the other non-variable costs, totdepcost are the depreciation costs, totcrewwage is the crew wage, totunpaidlab is the unpaid labour, totenercost are the energy costs, totrepcost are the repair costs and totvarcost are the other variable costs.

The opportunity costs of capital are calculated as the product of the tangible asset value (vessel depreciated replacement value, totdeprep) and the real interest rate

$$
\text { Oppcost }=\text { totdeprep } * \text { Reallnterest }
$$

The real interest rate is calculated using the long-term interest rate of the Member State $i$ and the inflation rate $n$ of the Member State for the year concerned: 


$$
\text { Reallnterest }=\frac{1+i}{1+n}-1
$$

Both the long-term interest rate and the inflation rate come from the European Central Bank (ECB).

\section{Interpretation}

If the ratio is greater than 1 , then enough income is generated to cover variable, fixed and capital costs, indicating that the segment is profitable, with potential undercapitalisation. Conversely, if the ratio is less than 1 , insufficient income is generated to cover variable, fixed and capital costs, indicating that the segment is unprofitable, with potential over-capitalisation.

In their review of the interpretation and reliability of the indicators, the EWG has expressed some concerns regarding the inactive vessel indicators, and has given some recommendations for improvement (see p.18 in STECF-19-13). The relevant concerns and recommendations are listed below:

- Presentation / interpretation of trends: due to the volatile nature of variable costs associated with fishing, the CR/BER indicator values may fluctuate considerably from one year to the next and commenting on trends which may be driven by the price of fuel for instance, does not necessarily help inform an assessment of fleet under- or over-capacity in relation to fishing opportunities.

- EWG 16-09 indicator preparatory meeting considers that whilst short term volatility is informative, in the long-term it is not. Moreover, the long-term approach overlaps with ROI or RoFTA. The long-term approach suggested in the guidelines should thus not be used and the EWG 16-09 balance indicator tables will as a result only present the short-term approach. EWG 16-09 reaffirms the need for a dedicated EWG to revise indicator guidelines.

Return on Investment and Return on Fixed Tangible Assets (RoI and RoFTA, \%)

According the 2014 Commission guidelines, the Return on Investment (ROI) or Return on Fixed Tangible Assets (RoFTA) indicator compares the long-term profitability of the fishing fleet segment to other available investments. ROI (also referred to as capital productivity) is the return of the investment divided by the cost of the investment. It measures profits in relation to the capital invested, i.e. it indicates how profitable a sector is relative to its total assets. The higher the return, the more efficient the sector is in utilizing its asset base.

When data on intangible assets (e.g. fishing rights, natural resource) are not available, the Return on Fixed Tangible Assets (ROFTA) is used as an approximation of ROI:

$$
\begin{gathered}
\text { ROI }=\frac{\text { CurrentRevenue }+ \text { totrightinc }-(\text { VariableCosts }+ \text { totrightcost }+ \text { totnovarcost }+ \text { totdepcost })}{\text { totdeprep }+ \text { totrights }} \\
\text { RoFTA }=\frac{\text { CurrentRevenue }-(\text { VariableCosts }+ \text { totnovarcost }+ \text { totdepcost })}{\text { totdeprep }}
\end{gathered}
$$

where CurrentRevenue is the income from landings and other income, VariableCosts include crew wage, unpaid labour, energy costs, repair costs and other variable costs and totnovarcost are the non-variable costs, totdepcost is the annual depreciation and totdeprep is the fleet depreciated replacement value as detailed in the CR/BER ratio calculation section above. The intangible assets (fishing rights) are included in the calculation of the ROI, totrightinc is the income from fishing rights, totrightcost are fishing right costs and totrights are the estimated value of fishing rights.

\section{Interpretation}

If ROI/RoFTA is smaller than the low-risk long term interest rates available elsewhere, then this suggests that the fleet segment may be overcapitalized. If ROI/RoFTA is less than zero and less than the best available long-term risk-free interest rate, this is an indication of long-term economic inefficiency that could indicate the existence of an imbalance. A traffic light approach is used:

- $\quad$ ROI $\geq$ target reference point (TRP) "in balance";

- $\quad 0 \leq R O I<$ TRP "not sufficiently profitable"

- $\quad \mathrm{ROI}<0$ "out of balance" 
There are inconsistencies in the definition of the target reference points between the different STECF expert working groups:

- The Annual Economic Report (AER; STECF, 2019b) uses TRP = real interest rate

- The Balance EWG follows the 2014 guidelines and uses TRP = 5-year average of the risk-free long-term interest rate (2012-2017)

The lack of homogeneity between the Balance EWG and the AER is noted in STECF 19-13 as an issue that will need to be solved by updating the guidelines.

\section{Net profit margin (\%)}

The net profit margin is the profit margin compared to the revenue of the fleet. It measures the economic performance of the fleet. It is calculated as the ratio of the net profit on the revenue:

$$
\text { NetProfitMargin }=\frac{\text { CurrentRevenue }-(\text { VariableCosts }+ \text { FixedCosts })}{\text { CurrentRevenue }}
$$

where CurrentRevenue is the income from landings and other income, VariableCosts include crew wage, unpaid labour, energy costs, repair costs and other variable costs and FixedCosts include non-variable costs, annual depreciation and opportunity costs as detailed in the CR/BER ratio calculation section above.

\section{Interpretation}

If the profit margin is positive, the fleet is considered viable, whereas if the profit margin is negative, the fleet is making an economic loss: profit margin $>0$ "in balance"; profit margin $\leq 0$ "out of balance".

\subsection{Comparison of results of the pelagic fleet segment}

In this section we present the indicators for the Dutch pelagic fleet segment (TM 40XX) from the national fleet report and from STECF-19-13. Both reports calculated the indicators and assessed the balance of the fleet in 2017 independently. We briefly describe and compare the results for each indicator, while in Section 3.3 we compare the methods behind the indicators, which will explain most of the differences between the national fleet report and STECF. The pelagic fleet segment was chosen as an example, since it is the only fleet segment that can be compared directly. The segmentation in the fleet report for the remaining part of the fleet was done differently from STECF (see Table 1 and Chapter 2).

\subsubsection{Biological indicators}

For the year 2017, the national fleet capacity reported a SHI value of 0.83 for the Dutch pelagic fleet segment (Table 4). Since the value was below 1 , the fleet report concluded that this was not a sign of imbalance. The indicator was calculated based on the most valuable stocks - eight stocks in total. STECF-19-13 found a considerably higher value of 1.13 (Table 4), which was based on the information of 22 stocks in total. Because the SHI was $>1$, STECF-19-13 reported that this segment may therefore not be in balance.

The number of stocks-at-risks in 2017 was calculated as 1 for the pelagic fleet segment in the national fleet report, whereas it was calculated as 2 by STECF-19-13 (Table 4). The fleet report explained that although there is a zero catch advice for the stock in question (herring west of Scotland and Ireland; her.27.6a7bc), since 2016, ICES advised that 4840 tonnes of catches can be obtained for a scientific monitoring fishery. The European Commission adjusted the TAC for this purpose to 5800 tonnes annually.

\subsubsection{Technical and economic indicators}

Table 5 shows the 2017 values of the five economic and technical indicators calculated at the fleet level for the Dutch pelagic fleet. While some differences are observed for the economic indicators, those are small and lead to the same conclusions, i.e. the fleet is in balance economically. The vessel utilization ratio is the same and there is no difference in the way the calculations are done. The inactive vessel 
indicator (calculated for the vessel length above $40 \mathrm{~m}$ ) shows some difference but is in balance in both cases.

\section{Table 4}

The Sustainable Harvest Indicator (SHI) and stocks-at-risk (SAR) indicator for the Dutch pelagic fleet segment in 2017 as calculated in the national fleet report and by STECF-19-13. The status on the balance of the fleet segment as reported in the fleet report and in STECF-19-13 is shown in the fourth and fifth column, whereas the main cause of difference is given in the last column (to be further discussed in Section 3.3.1).

\begin{tabular}{lccccc} 
Indicator & Fleet report & STECF-19-13 & Status fleet report & Status STECF-19-13 & Difference \\
SHI & 0.83 & 1.13 & In balance & Out of balance & $\begin{array}{c}\text { Wrong calculation } \\
\text { in fleet report }\end{array}$ \\
\hline SAR & 1 & 2 & $\begin{array}{c}\text { In line with ICES } \\
\text { advice to maintain } \\
\text { fishery for data } \\
\text { collection purpose }\end{array}$ & Out of balance & $\begin{array}{c}\text { Not all stocks of } \\
\text { fleet segment } \\
\text { included in fleet } \\
\text { report }\end{array}$ \\
\hline
\end{tabular}

\section{Table 5}

Summary of the 2017 economic and technical indicators in the 2019 National fleet report and STECF 19-13, the status derived from both sets of indicators and the difference in calculation

\begin{tabular}{lccccc} 
Indicator & $\begin{array}{c}\text { Fleet } \\
\text { report }\end{array}$ & $\begin{array}{c}\text { STECF-19- } \\
13\end{array}$ & $\begin{array}{c}\text { Status fleet } \\
\text { report }\end{array}$ & $\begin{array}{c}\text { Status STECF-19- } \\
13\end{array}$ & Difference \\
$\begin{array}{l}\text { Return on Investment } \\
\text { (ROI) }\end{array}$ & 7.8 & 7.2 & In balance & In balance & $\begin{array}{c}\text { Interest rates \& real } \\
\text { values }\end{array}$ \\
\hline $\begin{array}{l}\text { Break Even Revenue } \\
\text { Net Profit margin }\end{array}$ & 1.3 & 1.4 & In balance & In balance & $\begin{array}{c}\text { Interest rates \& real } \\
\text { values }\end{array}$ \\
\hline $\begin{array}{l}\text { Vessel utilization ratio } \\
\text { (VUR) }\end{array}$ & 7.7 & 9.2 & In balance & In balance & $\begin{array}{c}\text { Interest rates \& real } \\
\text { values }\end{array}$ \\
$\begin{array}{l}\text { Inactive vessel indicator* } \\
(40 X X)\end{array}$ & $11 \%$ & $1.1 \%$ & In balance & In balance & $\begin{array}{c}\text { Difference in } \\
\text { calculation }\end{array}$ \\
\hline
\end{tabular}

* the inactive vessel indicator is calculated per vessel length category, not per fleet. Here the length category is compared

In its analysis, STECF uses real values (corrected for inflation), while Wageningen Economic Research used nominal values. In addition, different interest rates have been used to calculate opportunity costs and compare to the Return on Investment.

The inactive vessel indicator was about 10 times higher in the national report compared to the value calculated by STECF. This is because of differences in the interpretation of the formula and in how the indicator was calculated.

\subsection{Comparison of fleet report methods with STECF}

Section 3.2 presented the differences in indicator values for the Dutch pelagic fleet segment in 2017 between the national fleet report and STECF-19-13. The current section tries to explain which difference in method has led to the discrepancy in indicator values with STECF-19-13.

\subsubsection{Biological indicators}

There are four reasons why the biological indicator values of the national fleet report differed from those reported by STECF. 
First of all, the national fleet report started their analysis by calculating the top $75 \%$ of species that contributed most to the total landings value of the fleet segment. They subsequently calculated the SHI and SAR indicator only for those top $75 \%$ of species. This step is not mentioned in the Commission guidelines and is neither taken by STECF. The fleet report in 2017 therefore included only 8 stocks (from 4 species) in their analysis of the pelagic fleet segment, whereas STECF-19-13 included 22 stocks (from 15 species). Although this will have contributed to the differences in indicator values, it most likely did not have a large impact on the SHI, since the species with the highest landing value were also the ones with the highest weight in the SHI calculation. Similarly, for stocks to be taken into consideration as a stock at risk (SAR), the landings (in weight) should at least be $10 \%$ of the total landings of the fleet segment, indicating that less important stocks will be excluded anyway. However, stocks may also be considered at risk when landings by a fleet segment comprise more than $10 \%$ of the total landings of a stock. For the pelagic fleet segment in 2017, this was the case for whiting West of Scotland (whg.27.6a), which was considered as a stock-at-risk by STECF-19-13, but not by the fleet report, because it was not taken into account in the analysis. This stock therefore explained the difference in SAR indicator between STECF (2) and the fleet report (1) for the pelagic fleet segment in 2017 (Table 2, Table 4).

Secondly, the national fleet report used the equation of the SHI calculation incorrectly. According to the equation, one should include only those stocks for which there are $F$ and $F_{\text {MSY }}$ values available. However, the fleet report used the total value of the landings from all stocks that were caught by the fleet segment in the denominator of the equation, instead of the sum of only those stocks with $\mathrm{F}$ and $\mathrm{F}_{\mathrm{MSY}}$ information. The nominator was therefore divided by a larger number, leading to a lower SHI in the fleet report compared to STECF (Table 2, Table 4). This was most likely the main cause of the discrepancy in the SHI values.

Thirdly, an important step in processing the landings data is dividing the landings per species over the stocks based on in which ICES sub-division landings were caught. STECF developed a method for this in 2016 by taking ICES landings data per stock from 2011 to 2015 (as ICES landings data also include non-EU countries) for cases where two (or more) stocks of the same species are caught in a sub-division. Based on the ratio between the ICES landings of the stocks in that sub-division, they calculated a splitting factor that could be applied to the landings data used to calculate the indicators. STECF-19-13 acknowledges that this method should be improved by calculating splitting factors for each year separately (as the splitting may vary between years) and by calculating them at the level of Member States rather than by pooling all countries together and apply the same factor to all countries. These recommendations are exactly what has been done in the national fleet report. Therefore, the different procedures of dividing the landings by species over the stocks most likely have led to some differences in the landings value per stock, which may have contributed to the discrepancy in biological indicator values between the fleet report and STECF-19-13.

Fourthly, for the pelagic fleet segment in 2017, the national fleet report did not take into account that landings of horse mackerel should be divided over three stocks instead of two: North Sea horse mackerel, western horse mackerel and Saharo-Mauritanean horse mackerel. The fleet report divided the landings only over the first two stocks, probably unaware of any landings of horse mackerel outside FAO area 27. Hence, the landings of the Saharo-Mauritanean stock were divided over the two other stocks. However, landings of the Saharo-Mauritanean stock (both in terms of value and weight) comprised less than $1 \%$ of the total landings, so the impact of this mistake on the SHI calculation has been very small.

To summarize, the differences in biological indicators were caused by: (i) the national fleet report selecting only the top $75 \%$ of most valuable species, (ii) a wrong interpretation of the SHI calculation, and (iii) by differences in underlying data caused by different methods of data handling and cleaning, (iv) particularly related to the dividing of landings data by species over stocks.

\subsubsection{Technical indicators}

The inactive vessel indicator was calculated differently. STECF-19-13 calculates the indicator for each length category related to the whole fleet (see Section 3.1.2). In the fleet report the indicator was calculated as the percentage of inactive vessels within each length category. As a result, the inactive vessel indicators per vessel length were much higher in the fleet report as in the STECF report. 
The vessel utilization ratio was calculated in the exact same way.

\subsubsection{Economic indicators}

Wageningen Economic Research followed the 2014 Commission guidelines for the calculation of the balance indicators which led to a few discrepancies with the STECF 19-13:

- In its analysis STECF uses real values (corrected for inflation) while Wageningen Economic Research used nominal values. Real values have been used by the Annual Economic Report working group since 2015, but the adjustment for inflation is not mentioned in the 2014 Commission guidelines.

- In the fleet report, the CR/BER was calculated using the long-term approach (including opportunity costs of capital), which is supposed to be calculated with the low risk long-term interest rate (as opposed to the real interest used in the Annual Economic Report). STECF-1913 has chosen to follow the AER method on this, explaining some discrepancies.

- In the calculation of ROI, the commercial value of fishing rights (income and costs of fishing rights) were excluded from the calculation in the 2014 Commission guidelines, while they are included in the STECF 19-13.

- Following the 2014 Commission guidelines, the ROI/RoFTA indicator is directly compared to the target reference point: ROI - low risk long term interest rate. This value (the difference of ROI and the long-term interest rate) was reported directly in the fleet report while STECF 19-13 reported the ROI.

Table 6

Different interest and inflation rates and harmonised index consumer price used in the fleet report and STECF 19-13 for the 2012-2017 period. The sources of raw data are the European Central Bank (ECB) or Eurostat, calculated rates are attributed to the report in which they were used.

\begin{tabular}{|c|c|c|c|c|c|c|c|c|}
\hline & 2012 & 2013 & 2014 & 2015 & 2016 & 2017 & Source & Usage \\
\hline Inflation NL (\%) & 2.8 & 2.6 & 0.3 & 0.2 & 0.1 & 1.3 & ECB & $\begin{array}{l}\text { STECF 19-13 Calculation } \\
\text { real interest rate }\end{array}$ \\
\hline $\begin{array}{l}\text { Low-risk long-term } \\
\text { interest rate } \mathrm{NL}(\%)\end{array}$ & 1.93 & 1.96 & 1.45 & 0.69 & 0.29 & 0.52 & ECB & $\begin{array}{l}\text { STECF 19-13 \& fleet } \\
\text { report Calculation real } \\
\text { interest rate }+5 \text { years } \\
\text { average }\end{array}$ \\
\hline $\begin{array}{l}\text { Real interest rate NL } \\
(\%)\end{array}$ & -0.85 & -0.62 & 1.15 & 0.49 & 0.19 & -0.77 & $\begin{array}{l}\text { STECF } \\
2019\end{array}$ & $\begin{array}{l}\text { STECF 19-13 Calculation } \\
\text { opportunity costs }\end{array}$ \\
\hline $\begin{array}{l}\text { 5-year average low-risk } \\
\text { long term interest rate } \\
(y-4, y)(\%)\end{array}$ & 3.166 & 2.712 & 2.264 & 1.804 & 1.264 & 0.982 & $\begin{array}{l}\text { STECF } \\
2019\end{array}$ & $\begin{array}{l}\text { STECF 19-13 } \\
\text { Comparison ROI }\end{array}$ \\
\hline $\begin{array}{l}5 \text {-year average long- } \\
\text { term interest rate }(y-3, \\
y+1)(\%)\end{array}$ & 2.713 & 2.266 & 1.806 & 1.267 & 0.983 & 0.707 & $\begin{array}{l}\text { Fleet } \\
\text { report }\end{array}$ & $\begin{array}{l}\text { Fleet report } \\
\text { Calculation opportunity } \\
\text { costs + Comparison ROI }\end{array}$ \\
\hline $\begin{array}{l}\text { Harmonised Index } \\
\text { Consumer Prices } \\
(2015=100)\end{array}$ & 96.99 & 99.47 & 99.79 & 100 & 100.11 & 101.4 & Eurostat & $\begin{array}{l}\text { STECF 19-13 } \\
\text { Calculation real values }\end{array}$ \\
\hline
\end{tabular}

As advised by STECF 19-13, Wageningen Economic Research has been using the 5-year average of the low risk long-term interest rate but using the latest data from y-3 to $y+1$ instead of $y-4$ to y (for 2017 the average 2014-2018 was used instead of 2013-2017). An overview of the different rates used is shown in Table 6. In the fleet report the 5-year average of the low risk long-term interest rate was used for both the calculation of the opportunity costs as to compare with the ROI while STECF 19-13 only used it to compare to ROI, the opportunity costs of capital being calculated with the real interest rate. In addition, STECF 19-13 used the Harmonised Index Consumer Prices $(2015=100)$ to adjust values for inflation. 


\subsection{Comparison of new fleet report methods with STECF}

Following the apparent differences between indicator values of the fleet report with those of STECF particularly for the biological indicators - the methods used for the national fleet report were improved by making sure they align with the interpretation of the Commission guidelines and the methods as described in STECF-19-13. All indicators were recalculated by using the same fleet segmentation as STECF has been using (Table 1) and by applying the same splitting procedure for the biological indicators as STECF-19-13 has used. This allows for a direct comparison of the indicators. Furthermore, the small differences that are still found between the indicator values will be explained whenever possible.

\subsubsection{Biological indicators}

\section{Sustainable Harvest Indicator}

A comparison of the newly calculated SHI for the fleet report with those of STECF-19-13 are presented in Table 7. For 7 out of 11 fleet segments, the same SHI value as STECF-19-13 was produced with the improved methods. For the remaining segments, the difference was relatively small $(<0.05)$, expect for segment DTS VL1824, for which there was also disagreement on if the $60 \%$-threshold was reached or not. Four fleet segments included the same number of stocks in the SHI calculation, whereas for the majority of fleet segments, STECF included more stocks than the fleet report (Table 7).

There are two main reasons why there are still differences between the newly calculated SHI values and STECF-19-13. The pelagic fleet segment will be taken again as the main example to illustrate these reasons, while at the end of this section also some explanation is given for some of the other fleet segments.

Firstly, there are three stocks of the pelagic fleet segment for which there were differences in the F/FMSY ratio that is used to calculate SHI. All three stocks, Norwegian spring spawning herring (her.27.124a514a), western horse mackerel (hom.27.2a4a5b6a7a-ce-k8) and Northeast Atlantic blue whiting (whb.27.1-91214), are assessed by the ICES Working Group on Widely Distributed Species (WGWIDE), which takes place in August and for which the advice comes out in October. Since STECF conducts their analyses before this working group's assessment, they used values from the 2018 assessment, while for the current analysis we used the most recent data from the 2019 assessment. When assessment data from 2018 were used, we calculated the same SHI for the pelagic fleet, namely 1.13 (Table 7). This indicates that the difference between the improved fleet report and STECF values for SHI is mainly caused by the input values for $F$ and $F_{M S Y}$ rather than by any potential differences in the value of the landings.

Secondly, for two stocks of the pelagic fleet segment, boarfish (boc.27.6-8) and Northeast Arctic saithe (pok.27.1-2), we were not able to find any values for $F$ and/or FMsr. We therefore only included 20 stocks in the calculation of the SHI (Table 7). However, STECF did include values for these stocks and thus used 22 stocks in total. Boarfish is a data-limited stock that does not have a full age-based assessment during which fishing mortality and fishing reference points are calculated. Northeast Arctic saithe is a data-rich stock with a full stock assessment, but advice is not based on $\mathrm{F}_{\mathrm{MSY}}$ (but on $\mathrm{F}_{\mathrm{pa}}$ ) and is therefore not estimated. It remains unclear where STECF got F/FMSY ratios for these two stocks from, but the relatively low value of the landings of these stocks for the pelagic fleet segment suggest that this discrepancy does not have a large impact on the SHI.

For the other fleet segments, the two explanations above will most likely apply as well. As we did for the pelagic fleet segment in the current analysis, a thorough analysis will have to done for the remaining 10 fleet segments to identify the stocks that have yet not been included in the improved fleet report analysis. For instance, the beam trawl segment and demersal trawl segment of 18-24 m vessel length (TBB VL2440 and DTS VL1824) have relatively high landings of Nephrops. However, Nephrops stocks have not yet been included in the improved fleet report analysis, thereby most likely partly explaining the difference in SHI for these fleet segments (Table 7). Including the missing stocks, together with $\mathrm{F}$ and $\mathrm{F}_{\mathrm{MSY}}$ values from the same assessment year, will most likely result in the same or very similar SHI values. 
Table 7

The Sustainable Harvest Indicator (SHI) as calculated with improved methods for the Dutch national fleet report and as reported by the EWG in STECF-19-13. Fleet segments and values in bold indicate that the $\boldsymbol{S H I}$ values are not the same. Red = out of balance $(S H I>1)$, green = in balance $(S H I<1)$. Values between parentheses indicate that there is no $\mathrm{F}$ and $\mathrm{F}_{\mathrm{MSY}}$ information available for at least $60 \%$ of the total landings value of the fleet segment, meaning that the SHI is not taken into account when assessing the balance of the fleet segment. The middle panel reports the number of stocks included in the SHI calculation. The righthand side of the table evaluates if the SHI for each fleet segment has the same value in the fleet report and STECF-19-13 (7th column), if the they reached agreement on if the threshold of $60 \% \mathrm{~F}$ and $\mathrm{F}_{\mathrm{MSY}}$ coverage was met ( $8^{\text {th }}$ column) and if the same number of stocks was included ( $9^{\text {th }}$ column). $Y=y e s, N=$ no (in bold).

\begin{tabular}{|c|c|c|c|c|c|c|c|c|}
\hline \multirow[t]{2}{*}{$\begin{array}{l}\text { Old fleet } \\
\text { segmentation }\end{array}$} & \multirow[t]{2}{*}{ Fleet segment } & \multicolumn{2}{|c|}{ SHI } & \multicolumn{2}{|c|}{ No. of stocks } & \multicolumn{3}{|c|}{ Difference in method } \\
\hline & & $\begin{array}{c}\text { Fleet } \\
\text { report }\end{array}$ & $\begin{array}{l}\text { STECF- } \\
19-13\end{array}$ & $\begin{array}{c}\text { Fleet } \\
\text { report }\end{array}$ & $\begin{array}{c}\text { STECF- } \\
19-13\end{array}$ & $\begin{array}{c}\text { Same } \\
\text { value? }\end{array}$ & $\begin{array}{l}\text { Agreement on } \\
\text { if threshold has } \\
\text { been reached? }\end{array}$ & $\begin{array}{c}\text { Same no. of } \\
\text { stocks? }\end{array}$ \\
\hline \multirow{4}{*}{ Small scale } & TBB VL0010 & $(0.96)$ & $(0.96)$ & 8 & 8 & $Y$ & $\mathrm{Y}$ & $Y$ \\
\hline & DFN VL1824 & $(1.08)$ & $(1.08)$ & 5 & 5 & $\mathrm{Y}$ & $\mathrm{Y}$ & $Y$ \\
\hline & PG VL0010 & 0.66 & 0.66 & 10 & 10 & Y & $\mathrm{Y}$ & $Y$ \\
\hline & PG VL1012 & 1.04 & 1.04 & 7 & 8 & $Y$ & $\mathrm{Y}$ & $\mathbf{N}$ \\
\hline \multirow{2}{*}{ Demersal } & DTS VL1824 & $(0.98)$ & 1.07 & 15 & 18 & $\mathbf{N}$ & $\mathbf{N}$ & $\mathbf{N}$ \\
\hline & DTS VL2440 & $(1.09)$ & $(1.11)$ & 21 & 25 & $\mathbf{N}$ & $\mathrm{Y}$ & $\mathbf{N}$ \\
\hline \multirow{2}{*}{$\begin{array}{l}\text { Small beam } \\
\text { trawlers }\end{array}$} & TBB VL1218 & $(0.77)$ & $(0.77)$ & 5 & 5 & $Y$ & $\mathrm{Y}$ & $\mathrm{Y}$ \\
\hline & TBB VL1824 & $(1.07)$ & $(1.07)$ & 13 & 15 & $Y$ & $Y$ & $\mathbf{N}$ \\
\hline \multirow{2}{*}{$\begin{array}{l}\text { Large beam } \\
\text { trawlers }\end{array}$} & TBB VL2440 & 1.03 & 1.05 & 12 & 15 & $\mathbf{N}$ & $\mathrm{Y}$ & $\mathbf{N}$ \\
\hline & TBB VL40XX & 1.03 & 1.03 & 12 & 16 & $Y$ & $\mathrm{Y}$ & $\mathbf{N}$ \\
\hline Pelagic & TM VL40XX & 1.09 & 1.13 & 20 & 22 & $\mathbf{N}$ & $Y$ & $\mathbf{N}$ \\
\hline
\end{tabular}

\section{Stocks-at-risk indicator}

Table 8 presents the SAR indicator values for the 11 Dutch fleet segments in 2017 as calculated with the improved methods for the national fleet report and as reported in STECF-19-13. There are a few differences with several possible explanations.

For the larger beam trawler segments (TBB VL2440 and TBB VL40XX) the improved fleet report considered starry ray (rjr.27.23a4) as a stock at risk, as the fleets each caught more than $10 \%$ of the landings of this stock in 2017 ( $21 \%$ and $44 \%$, respectively). Although STECF-19-13 also considers starry ray to be at risk due to zero catch advice for 2017 (criterion B), apparently, they did not find the landings for this stock to be more than $10 \%$ for neither of the two fleet segments. This might be due to a difference in the weight of the landings between the fleet report analysis and STECF-19-13, which in turn may lead to different conclusions regarding if a stock is exploited or not (Section 3.1.1). In contrast to the value of the landings, the weight of the landings used in STECF-19-13 has not been made publicly available. It is therefore not possible to say if and how much this has contributed to the difference in the SAR indicator values. This should therefore be further investigated in close cooperation with STECF.

For the pelagic fleet segment (NLD-NAO-TM-VL4OXX-NGI), the improved fleet report analysis resulted in one additional stock to be at risk, namely western horse mackerel (hom.27.2a4a5b6a7a-ce-k8). As for the SHI, this is because the improved fleet report analysis made use of the most recent assessment (2019) during which was observed that the stock is currently below Blim. This was not yet the case in the 2018 assessment, which the STECF-19-13 used as a source. Hence, when using the same assessment data as STECF-19-13, the new fleet report methods come to the same SAR value for the pelagic fleet.

To summarize, the main causes for the differences in the biological indicator values between the improved fleet report analysis and STECF-19-13 were most likely due to: (i) the improved fleet report made use of more recent stock assessment information; (ii) different numbers of stocks included in the calculations; and (iii) differences in value of the landings. Besides these, there are some other possible 
explanations that need to be further investigated in close cooperation with the EWG of STECF-19-13 (e.g. inclusion or exclusion of some stocks in the SHI and the SAR indicator, potential difference in weight of the landings).

\section{Table 8}

The stocks-at-risk (SAR) indicator for the Dutch fleet segments in 2017 as calculated with the improved methods for the national fleet report and as reported by the EWG in STECF-19-13. Text and values in bold indicate that there is a difference in the SAR indicator for a fleet segment. The status on the balance of the fleet segment as would be reported by the fleet report and as reported in STECF-19-13 is shown in the two columns on the right.

\begin{tabular}{llcccc}
\multirow{2}{*}{$\begin{array}{l}\text { Old fleet } \\
\text { segmentation }\end{array}$} & Fleet segment & Fleet report & STECF-19-13 & Fleet report & STECF-19-13 \\
\hline \multirow{3}{*}{ Small scale } & TBB VL0010 & 0 & 0 & in balance & in balance \\
\cline { 2 - 6 } & DFN VL1824 & 0 & 0 & in balance & in balance \\
\cline { 2 - 6 } & PG VL0010 & 1 & 1 & out of balance & out of balance \\
\cline { 2 - 6 } PG VL1012 & 0 & 0 & in balance & in balance \\
\hline \multirow{2}{*}{$\begin{array}{l}\text { Semersal } \\
\text { trawlers }\end{array}$} & DTS VL1824 & 0 & 0 & in balance & in balance \\
\hline & DTS VL2440 & 0 & 0 & in balance & in balance \\
\hline \multirow{2}{*}{ Large beam } & TBB VL1218 & 0 & 0 & in balance & in balance \\
trawlers & TBB VL1824 & 0 & 0 & in balance & in balance \\
\cline { 2 - 6 } Pelagic & TBB VL40XX & $\mathbf{1}$ & $\mathbf{0}$ & out of balance & in balance \\
\hline
\end{tabular}

\subsubsection{Technical and economic indicators}

\section{Inactive Vessel Indicator}

Using the total fleet as denominator, we obtain exactly the same inactive vessel indicator values (Table 9). The percentage of inactive vessels for the total fleet is out of balance due to the high number of small inactive vessels. When looking in gross tonnage or power, the Dutch fleet is in balance for the inactive vessel indicators.

\section{Table 9}

The inactive vessel indicators for the Dutch fleet in 2017 as calculated with the improved methods for the national fleet report and as reported by the EWG in STECF-19-13. Indicators in green are "in balance" and the red ones are "out of balance".

\begin{tabular}{l|cc|cc|cc}
\hline & \multicolumn{2}{|c}{ Fleet segment Inactive vessels } & \multicolumn{2}{c}{$\%$ Inactive GT } & \multicolumn{2}{c}{$\%$ Inactive $\mathrm{kW}$} \\
& \multicolumn{1}{|c|}{ Fleet report } & STECF-19-13 & \multicolumn{1}{c}{ Fleet report } & STECF-19-13 & Fleet report & STECF-19-13 \\
\hline VL0010 & 19.16 & 19.16 & 0.21 & 0.21 & 2.07 & 2.07 \\
\hline VL1012 & 1.77 & 1.77 & 0.11 & 0.11 & 0.83 & 0.83 \\
\hline VL1218 & 2.72 & 2.72 & 0.35 & 0.35 & 1.15 & 1.15 \\
\hline VL1824 & 1.77 & 1.77 & 0.53 & 0.53 & 0.98 & 0.98 \\
\hline VL2440 & 2.17 & 2.17 & 1.56 & 1.56 & 1.87 & 1.87 \\
\hline VL40XX & 1.09 & 1.09 & 1.63 & 1.63 & 2.12 & 2.12 \\
\hline total & 28.68 & 28.68 & 4.39 & 4.39 & 9.02 & 9.02 \\
\hline
\end{tabular}

\section{Vessel Utilization Ratio}

The Vessel Utilization Ratio was calculated exactly as in STECF 19-13, leading the same indicator values (Table 10). Out of the 11 fleets, five are out of balance according to this indicator:

- $\quad$ Three small scale fleets for which caution is always advised according to STECF 19-13 and 
- $\quad$ Two small beam trawler fleets which fish mainly for shrimp and some vessels also target flatfish leading to a difference in total days at sea within the fleet for the two categories of vessels as the shrimp effort is limited.

\section{Table 10}

The vessel utilization ratio for the Dutch fleets in 2017 as calculated with the improved methods for the national fleet report and as reported by the EWG in STECF-19-13. Indicators in green are "in balance" and the red ones are "out of balance".

\begin{tabular}{llcc}
\multirow{2}{*}{$\begin{array}{l}\text { Old fleet } \\
\text { segmentation }\end{array}$} & Fleet segment & \multicolumn{2}{c}{ VUR } \\
\hline \multirow{3}{*}{ Small scale } & TBB VL0010 & 0.6 & 0.6 \\
\cline { 2 - 4 } & DFN VL1824 & 1.1 & 1.1 \\
\cline { 2 - 4 } & PG VL0010 & 0.2 & 0.2 \\
\cline { 2 - 4 } & PG VL1012 & 0.6 & 0.6 \\
\hline \multirow{2}{*}{ Demersal } & DTS VL1824 & 1.1 & 1.1 \\
\cline { 2 - 4 } & DTS VL2440 & 0.8 & 0.8 \\
\hline Small beam & TBB VL1218 & 0.2 & 0.2 \\
\cline { 2 - 4 } trawlers & TBB VL1824 & 0.6 & 0.6 \\
\hline Large beam & TBB VL2440 & 0.8 & 0.8 \\
\cline { 2 - 4 } trawlers & TBB VL40XX & 0.7 & 0.7 \\
\hline Pelagic & TM VL40XX & 1.0 & 1.0 \\
\hline
\end{tabular}

\section{Economic indicators}

All the economic indicators were calculated exactly as in STECF 19-13 (Table 11). Most fleets are in balance except the smaller demersal trawlers (DTS VL1824 - all indicators out of balance) and the small beam trawler fleet (TBB VL0010 - ROI <0). The fleet of the small demersal trawlers only had 8 vessels left in 2017 and it is therefore questionable whether enough data was available. The small beam trawlers are part of the small scale fishery for which we have less reliable economic data collected by questionnaires.

\section{Table 11}

The economic indicators for the Dutch fleet in 2017 as calculated with the improved methods for the national fleet report and as reported by the EWG in STECF-19-13. Indicators in green are "in balance" and the red ones are "out of balance". CR/BER >1 in balance; ROI $>$ TRP in balance; Net Profit Margin $>0$ in balance.

\begin{tabular}{|c|c|c|c|c|c|c|c|}
\hline \multirow[t]{2}{*}{$\begin{array}{l}\text { Old fleet } \\
\text { segmentation }\end{array}$} & \multirow[t]{2}{*}{ Fleet segment } & \multicolumn{2}{|c|}{ CR/BER } & \multicolumn{2}{|c|}{$\mathrm{ROI}(\mathrm{TRP}=0.707)$} & \multicolumn{2}{|c|}{ Net Profit Margin \% } \\
\hline & & Fleet report & STECF-19-13 & $\begin{array}{l}\text { Fleet } \\
\text { report }\end{array}$ & $\begin{array}{c}\text { STECF- } \\
19-13\end{array}$ & $\begin{array}{l}\text { Fleet } \\
\text { report }\end{array}$ & $\begin{array}{c}\text { STECF- } \\
19-13\end{array}$ \\
\hline \multirow{4}{*}{ Small scale } & TBB VL0010 & 1.05 & 1.05 & -0.2 & -0.2 & 3 & 3 \\
\hline & DFN VL1824 & 2.73 & 2.73 & 3.2 & 3.2 & 36 & 36 \\
\hline & PG VL0010 & 1.73 & 1.73 & 7 & 7 & 22.7 & 22.7 \\
\hline & PG VL1012 & 1.73 & 1.73 & 6.3 & 6.3 & 22.7 & 22.7 \\
\hline \multirow{2}{*}{ Demersal } & DTS VL1824 & 0.97 & 0.97 & -2.2 & -2.2 & -1.2 & -1.2 \\
\hline & DTS VL2440 & 1.81 & 1.81 & 14.4 & 14.4 & 16.5 & 16.5 \\
\hline \multirow{2}{*}{$\begin{array}{l}\text { Small beam } \\
\text { trawlers }\end{array}$} & TBB VL1218 & 4.34 & 4.34 & 96.3 & 96.3 & 28.7 & 28.7 \\
\hline & TBB VL1824 & 1.71 & 1.71 & 16.9 & 16.9 & 14.9 & 14.9 \\
\hline \multirow{2}{*}{$\begin{array}{l}\text { Large beam } \\
\text { trawlers }\end{array}$} & TBB VL2440 & 2.27 & 2.27 & 19.7 & 19.7 & 20.8 & 20.8 \\
\hline & TBB VL40XX & 2.84 & 2.84 & 12.9 & 12.9 & 24.2 & 24.2 \\
\hline Pelagic & TM VL40XX & 1.39 & 1.39 & 7.2 & 7.2 & 9.2 & 9.2 \\
\hline
\end{tabular}




\section{$4 \quad$ Conclusion and Recommendations}

This report investigated the discrepancy in balance indicator values from 2017 as reported in the Dutch national fleet report and by the Balance EWG in STECF-19-13. We aimed to explain the observed differences, and we re-calculated the indicators for the national fleet report on the 2017 data with the same fleet segmentation as STECF is using. A summary of the findings is presented in Table 12 , including explanations of the observed differences and/or recommendations for future national fleet reports to avoid discrepancies as much as possible in the future. Some further details regarding the observed differences in methods and recommendations are given below.

\section{Table 12}

Summary of the old and future methods of the fleet report in comparison to the STECF approach, explanations for the observed differences for each indicator and/or future work needed to avoid discrepancies in the future and to develop the new fleet report methods further.

\begin{tabular}{|c|c|c|c|c|c|}
\hline & Indicator & STECF & Old method fleet report & Future method fleet report & Explanation \\
\hline Fleet & all & $\begin{array}{l}\text { STECF } \\
\text { segmentation }\end{array}$ & $\begin{array}{l}\text { Clustering of fleets } \\
\text { (Table } 1 \text { and Table } 3 \text { ) }\end{array}$ & $\begin{array}{l}\text { STECF segmentation } \\
\text { for all indicators, } \\
\text { clustering of fleets also } \\
\text { for economic indicators }\end{array}$ & $\begin{array}{l}\text { To be consistent and of use for } \\
\text { the Balance EWG, indicators } \\
\text { will be also provided at the } \\
\text { STECF fleet segmentation level }\end{array}$ \\
\hline \multirow[t]{2}{*}{ Biological } & SHI & & $\begin{array}{l}\text { Wrong interpretation of } \\
\text { equation, only top } 75 \% \\
\text { of most valuable } \\
\text { species analysed, } \\
\text { different splitting } \\
\text { method of landings } \\
\text { data into stocks }\end{array}$ & $\begin{array}{l}\text { As STECF, but not all } \\
\text { stocks yet included in } \\
\text { analysis, most recent } \\
\text { assessments used }\end{array}$ & $\begin{array}{l}\text { Further work needed to } \\
\text { include all stocks in national } \\
\text { fleet report analysis, } \\
\text { incorporate division of landings } \\
\text { across stocks based on annual } \\
\text { landings and landings by } \\
\text { country }\end{array}$ \\
\hline & SAR & & $\begin{array}{l}\text { Only top } 75 \% \text { of most } \\
\text { valuable species } \\
\text { analysed, different } \\
\text { splitting method of } \\
\text { landings data into } \\
\text { stocks }\end{array}$ & $\begin{array}{l}\text { As STECF, but most } \\
\text { recent assessments } \\
\text { used, potential } \\
\text { difference in landings } \\
\text { (in weight) }\end{array}$ & $\begin{array}{l}\text { Further work needed in close } \\
\text { cooperation with STECF to } \\
\text { explain the difference, } \\
\text { incorporate division of landings } \\
\text { across stocks based on annual } \\
\text { landings and landings by } \\
\text { country }\end{array}$ \\
\hline \multirow[t]{2}{*}{ Technical } & $\begin{array}{l}\text { Inactive } \\
\text { vessels }\end{array}$ & $\begin{array}{l}\text { Division by the } \\
\text { total for the } \\
\text { whole Dutch fleet }\end{array}$ & $\begin{array}{l}\text { Division by the total per } \\
\text { vessel length }\end{array}$ & Exactly as STECF & \\
\hline & VUR & & Old fleet segmentation & Exactly as STECF & \\
\hline \multirow[t]{3}{*}{ Economic } & CR/BER & $\begin{array}{l}\text { Real interest rate } \\
\text { for the calculation } \\
\text { of opportunity } \\
\text { costs and real } \\
\text { values corrected } \\
\text { for inflation }\end{array}$ & $\begin{array}{l}\text { Using long term } \\
\text { interest rate and } \\
\text { nominal values }\end{array}$ & Exactly as STECF & \multirow{2}{*}{$\begin{array}{l}\text { STECF } 19-13 \text { points out that } \\
\text { there are some discrepancies in } \\
\text { the methods in the } 2014 \\
\text { guidelines and what is used by } \\
\text { the Annual Economic Report. } \\
\text { The guidelines should be } \\
\text { corrected to reflect exactly } \\
\text { what is been done in the } \\
\text { Balance EWG. }\end{array}$} \\
\hline & ROI & $\begin{array}{l}\text { Include } \\
\text { commercial value } \\
\text { of fishing rights } \\
\text { and real values } \\
\text { corrected for } \\
\text { inflation }\end{array}$ & $\begin{array}{l}\text { No value of fishing } \\
\text { rights and nominal } \\
\text { values }\end{array}$ & Exactly as STECF & \\
\hline & $\begin{array}{l}\text { Net profit } \\
\text { margin }\end{array}$ & & not provided & Exactly as STECF & \\
\hline
\end{tabular}


Overall, the fleet segmentation was a major difference in the methods of the national fleet report and STECF-19-13. Although the more clustered segmentation of the old national fleet report can be justified because of the quality and reliability of the economic data for some fleets, we will also provide the indicators for all fleet segments (i.e. for those from the STECF segmentation) for the new fleet report, and then to provide context in the fleet report regarding the quality and reliability of the underlying data, particularly for the economic indicators.

\section{Reflection on the indicators}

When interpreting the indicators and drawing conclusions on the balance between capacity and fishing opportunities, it remains important to keep in mind the lack of consensus on the interpretation of the indicators and the critique of the Balance EWG on the capability of the indicators to reflect this balance (see STECF19-13 and Section 3.1). As STECF-19-13 states on p. 11-12:

"[...] none of the indicators used in isolation are reliable indicators of the balance between fleet capacity and fishing opportunities. Furthermore, for a particular fleet segment, the different indicator values may give conflicting signals e.g. some indicator values may be favourable, and others may be unfavourable. While each of the indicators are potentially useful to highlight certain aspects of a fleet segment, even if they are used collectively, other criteria need to be taken into account to arrive at an assessment of balance between fleet capacity and fishing opportunities. Nevertheless, the indicators can potentially inform Member States on fleet management."

Furthermore, STECF-19-13 announced that the EWG plans to undertake an extensive review in 2020 of the current biological indicators and underlying that data are used. This may lead to a revision of the 2014 Commission guidelines, including some new biological indicators.

\section{Recommendations}

As previously mentioned, there are still some small differences between the biological indicators of the updated fleet report and STECF-19-13. Differences in the SHI are likely due to stocks that are not yet included in the new methods of the national fleet report. It is thus necessary to include these stocks in future fleet reports. Regarding the SAR indicator, it remains unclear what causes the differences with STECF-19-13. Continuing contact and close cooperation with the members of the Balance EWG is considered relevant. We therefore recommend sending a person with biological expertise on behalf of the Netherlands to the next meeting of the EWG.

The interpretation of the economic and technical indicators is highly dependent on the context, especially for small-scale fisheries where fishing may not always be the main activity to gain income. STECF-1913 acknowledges that local knowledge of the fisheries is needed to interpret the economic and technical indicators. It is therefore recommended to ensure this local knowledge and context about the Dutch small-scale fleet segment and others is provided either through the national fleet report or by sending a local expert to the Balance EWG meeting.

One of the potential causes of difference in biological indicator values between the old fleet report and STECF-19-13 was a different procedure of splitting the landings data by species over the stocks. With the new fleet report methods, the same splitting procedure was followed as STECF, which is based on ICES landings from 2011-2015. As STECF-19-13 acknowledge themselves, this method should be improved by splitting data annually and by Member State, which the old fleet report method was already doing. Future work is needed to investigate the effect of this preferred splitting procedure when using the new fleet segmentation and incorporate it into the new fleet report analysis as a better alternative than the current procedure STECF is using.

The Common Fisheries Policy emphasizes the need to maintain a balance of the fishing fleet capacity over time. The Commission guidelines therefore consider it appropriate to present the indicators in the context of previous years. Until now, this was lacking for the biological indicators in the national fleet report, and it is therefore recommended to do so in future fleet reports, as it provides context for assessing the balance of fleet segments. For instance, the SHI has remained above 1 for the large beam trawler segment TBB VL40XX since 2008, but it has been steadily declining from 1.87 in 2008 to 1.03 in 2017 , according to STECF-19-13. This declining trend may indicate that, despite SHI $>1$, the balance 
of the fleet segment is improving and that it is on its way of meeting the goals of the CFP and achieving balance. 


\section{References}

Communication from the Commission to the European Parliament and the Council - Guidelines for the analysis of the balance between fishing capacity and fishing opportunities according to Art 22 of Regulation (EU) No 1380/2013 of the European Parliament and the Council on the Common Fisheries Policy COM(2014) 545 final.

MARE/A4/ACS. 2019. Data call for economic and social datasets on the EU fishing fleets. 7p.

Scientific, Technical and Economic Committee for Fisheries (STECF). 2019a. Assessment of balance indicators for key fleet segments and review of national reports on Member States efforts to achieve balance between fleet capacity and fishing opportunities (STECF-19-13); Publications Office of the European Union, Luxembourg, 2019.

Scientific, Technical and Economic Committee for Fisheries (STECF). 2019b: The 2019 Annual Economic Report on the EU Fishing Fleet (STECF 19-06), Carvalho, N., Keatinge, M. and Guillen Garcia, J. editor(s), EUR 28359 EN, Publications Office of the European Union, Luxembourg, 2019.

Taal, C., Bartelings, H., Beukers, R., Klok, A. J., and W. J. Strietman. 2010. Visserij in cijfers 2010. 2010-057. (In Dutch) 


\section{Acknowledgements}

We thank Jerome Guitton, Armelle Jung and Giuseppe Scarcella - members of the STECF Balance Expert Working Group - for their help with interpreting the biological indicators and the differences in the biological indicator values between STECF-19-13 and the Dutch national fleet report. We thank Karolina Molla Gazi for her help in dividing the landings data by species and by ICES sub-division over the stocks. 


\section{Justification}

Report C045/20

Project Number: BO-43-023.02-052

The scientific quality of this report has been peer reviewed by a colleague scientist and a member of the Management Team of Wageningen Marine Research

Approved: $\quad$ Ir. N.T. Hintzen

Researcher

Signature:

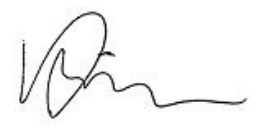

Date: $\quad$ 8th of May, 2020

Approved: $\quad$ Drs. J. Asjes

Manager Integration

Signature:

Date:

8th of May, 2020 
Wageningen Marine Research

T +31(0)317480900

E: marine-research@wur.nl

www.wur.eu/marine-research

Visitors' address

- Ankerpark 271781 AG Den Helder

- Korringaweg 7, 4401 NT Yerseke

- Haringkade 1, 1976 CP IJmuiden
With knowledge, independent scientific research and advice, Wageningen Marine Research substantially contributes to more sustainable and more careful management, use and protection of natural riches in marine, coastal and freshwater areas.

Wageningen Marine Research is part of Wageningen University \& Research. Wageningen University \& Research is the collaboration between Wageningen University and the Wageningen Research Foundation and its mission is: 'To explore the potential for improving the quality of life' 